\title{
The Impact of Digitalization on Processes and Organizational Structures of Architecture and Engineering Firms
}

\author{
Cinzia Talamo and Marcella M. Bonanomi
}

\begin{abstract}
The digitalization of the architecture, engineering, and construction (AEC) industry leads to new forms of process through which buildings are designed, constructed, and operated, and to new forms of organization through which professionals work and interact. Certain activities of the conventional building process disappear, while others appear, distribution of work is reviewed, and new relationships, roles, and responsibilities emerge. Although many architecture and engineering $(\mathrm{A} / \mathrm{E})$ firms claim that they have already undertaken a digital transformation, there is still little awareness of the new forms of process and organization associated with digitalization. This lack of knowledge about the process-oriented and organizational changes makes it difficult to establish a work environment within and between firms that is conducive to digital innovation. Given the above considerations, the main objective of this research project has been to understand the process-oriented and organizational changes that the adoption of digital technologies bring on, as well as the new forms of process and organization associated with the digital transformation of architectural and engineering firms. To achieve this, a case-study analysis of two $\mathrm{A} / \mathrm{E}$ firms — one in Italy and one in Canada — has been performed.
\end{abstract}

\section{Introduction}

Productivity growth in the architecture, engineering, and construction (AEC) industry has stagnated globally in recent decades (Barbosa et al. 2017). The AEC industry has not been able to keep pace with the overall economic productivity growth. A recent report by McKinsey (Remes et al. 2018) finds a positive correlation between the productivity growth of an industry and its degree of digitalization. However,

\footnotetext{
C. Talamo $(\bowtie)$

Architecture, Built Environment and Construction Engineering-ABC Department, Politecnico di Milano, Milan, Italy

e-mail: cinzia.talamo@polimi.it
}

M. M. Bonanomi

Chair of Innovative and Industrial Construction, ETH Zurich, Zurich, Switzerland

(C) The Author(s) 2020

B. Daniotti et al. (eds.), Digital Transformation of the Design, Construction and Management Processes of the Built Environment, Research for Development, https://doi.org/10.1007/978-3-030-33570-0_16 


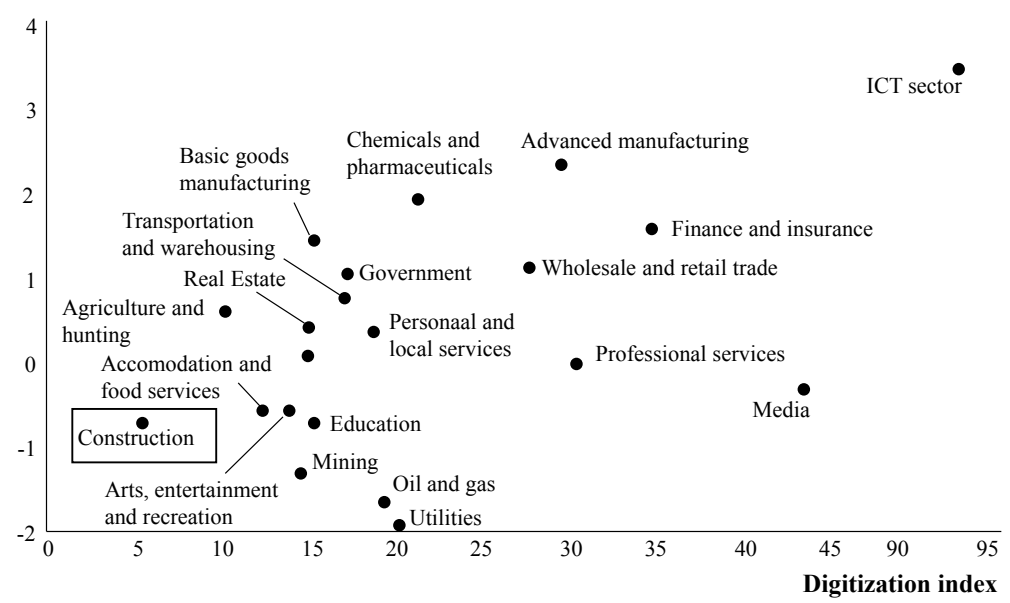

Fig. 1 Correlation between productivity growth and digitization index across industries in Europe: highlighted in the red box the construction industry (Remes et al. 2018)

according to the McKinsey 'digitization index', construction is among the least digitized sectors in the world: it comes second to last in the United States-right after the agriculture and hunting industry - and last in Europe (see Fig. 1).

Italy and Canada have not been an exception to this trend (Remes et al. 2018). Italy ranks behind other nations in digitalization, ${ }^{1}$ ranking 15 th out of 21 nations $^{2}$ and behind countries such as Finland, Netherlands, and Ireland-in a recent study about building information modeling (BIM) adoption (Kassem and Succar 2017). According to the same study, Canada performs slightly better, ranking 11th. To investigate the level of BIM diffusion, this study overlays three BIM fields (technology, process, and policy) with as many BIM capability stages (modeling, collaboration, and integration) to generate nine diffusion $\operatorname{areas}^{3}$ (Succar and Kassem 2017). The results show an irregular distribution of the diffusion rates across the 21 countries analyzed (see Fig. 2). For example, in the Netherlands, the United Kingdom, China, Finland, and South Korea, the diffusion is quite balanced across the nine diffusion areas. On the contrary, Italy and Canada, like Malaysia, Mexico, Russia, Spain, Switzerland, Qatar, and the UAE, show unbalanced diffusion rates. Additionally, some diffusion areas are missing in these countries. This is the case, for example,

\footnotetext{
${ }^{1}$ By 'digitalization', we mean the transformation of processes, organizational settings, and project delivery methods that need to be coupled with the adoption of digital technologies in order to gain the full benefits of the digitalization of the architecture, engineering, and construction industry.

${ }^{2}$ USA. United Kingdom, UAE, Switzerland, Spain, South Korea, Russia, Qatar, Portugal, New Zealand, Netherlands, Mexico, Malaysia, Italy, Ireland, Hong Kong, Finland, China, Canada, Brazil, Australia.

${ }^{3}$ Modeling technologies, modeling processes, modeling policies, collaboration technologies, collaboration processes, collaboration policies, integration technologies, integration processes, integration policies.
} 




Fig. 2 Rates of the nine diffusion areas of BIM adoption across the 21 countries analyzed: highlighted in the red boxes Italy and Canada (Kassem and Succar 2017)

of the diffusion area 'integration policies' in Italy. Furthermore, Italy shows a significant difference between the technologies-related diffusion rates (colored in blue, purple, and light blue in Fig. 1) and the 'processes' and 'policies' ones. Canada shows a similar trend, but it is not missing any diffusion area. Kassem and Succar (2017) argue that a country with either an unbalanced distribution or missing diffusion area would possibly face different adoption challenges compared to a country with all the nine areas established and well distributed. Overall, this study shows the predominance of the 'modeling technologies' and 'modeling processes' diffusion areas, while minor rates are associated with 'collaboration/integration processes' and 'collaboration/integration policies'. These results point out the industry's tendency to focus more on the adoption of digital technologies and the related modeling processes, and less on the collaboration and integration processes and policies required to gain the full benefits of digitalization.

Besides the poor understanding of the collaboration and integration processes required to support digital innovation, also the organizational changes associated with digitalization are not understood fully yet. On the contrary, a recent report by the Boston Consulting Group (2016) argues the importance to couple organizational 
changes with process-oriented ones in order to leverage the full benefits of digitalization. When processes and technologies mature digitally, organizations should change accordingly and move toward networked organizational forms that are more conducive to collaboration and integration within and between firms (Picon 2016). Regarding the multidimensional nature of the changes brought on by digitalization, Poirier et al. (2015) proposes a conceptual framework, which is organized into three fields of change: technology, process, and organization. Author's belief is that the digital transformation requires a balanced distribution and management of changes in technology, process, and organizational setting. Furthermore, she underlines the importance of coupling these fields of change with a full understanding of the context of change, as well as the stage of implementation.

Starting from these considerations and aware of the significant effort already devoted from both researchers and practitioners on digital technologies and the related modeling processes, the overall objective of this research project has been rather to understand the process-oriented and organizational changes that the adoption of digital technologies bring on within architectural and engineering firms. To reach this overall objective, the project has focused on two distinct, but complementary levels (specific objectives):

1. The process-oriented changes that the adoption of digital technologies bring on within architectural and engineering firms and the new forms of process facilitating the achievement of the full benefits of digitalization;

2. The organizational changes that the adoption of digital technologies bring on within architectural and engineering firms and the new forms of organization facilitating the achievement of the full benefits of digitalization.

\section{Research Approach}

To achieve this, the research project has employed a mixed-method case-study approach. Case studies are a suitable methodology for explanatory research as they can help to answer the 'how' and 'why' questions related to a topic, especially when an in-depth analysis and observation is performed (Burawoy 1998; Eisenhardt 1989). The case-study selection for the purpose of this study included one architectural and engineering firm headquartered in Italy $(<250$ employees) and one in Canada $(\geq 250$ employees). The following reasons can justify the choice of an Italian and a Canadian firm:

- Both the Italian and the Canadian AEC industries cannot be considered first movers in digitalization. They shall rather be understood as evolving contexts still in transition; 
- Both the Italian ${ }^{4}$ and the Canadian ${ }^{5}$ industries' workforce are mainly composed of small and medium firms (European Builders Confederation; Industry Canada 2014; Leung et al. 2008).

For clarity purposes, it must be underlined that this study has analyzed the two case studies distinctly and separately. Each of the case study focused on one of the two fields of change associated with digitalization: one case study on the process-oriented changes and the other one on the organizational ones. Specifically, in the analysis of the Italian firm, the multimethod approach adopted to perform the experimental research has meant investigating the process-oriented changes in practice through mixed-methods of data collection: observation, unstructured interviews, and process mapping. In the case of the Canadian firm, observation, surveys, and social network analysis (SNA) (Chinowsky et al. 2008, 2012; Zheng et al. 2016) have been rather used as methods to identify how digital transformation affects the organizational setting.

In both the case studies, the process of data collection, data analysis, and data representation has been performed by focusing on three different, but complementary, states of change:

1. 'As-is' state. This step included data collection, analysis, and representation of the conventional design process and existing organizational structure;

2. 'Transition' state. This phase included data collection, analysis, and representation of the design process and organizational structure in place at the time of the first adoption of digital technologies;

3. 'To-be' state. This step included data collection, analysis, and representation of the envisioned digital design process and organizational structure to be achieved in order to gain the full benefits of digitalization.

One difference between the two case studies is that the analysis of the Italian firm has been performed at the project level. This has meant collecting, analyzing, and representing the changes of the design process implemented in the context of a project. The analysis of the Canadian firm has been rather performed at the company level. This has meant collecting, analyzing, and representing the changes of the organization itself and not in the context of a project.

\footnotetext{
${ }^{4}$ Italian small and medium enterprises (SMEs) account for $80 \%$ of the total share of nominal GDP in the construction industry. Small businesses only make up 70\% of the Italian construction industry's workforce (European Builders Confederation).

${ }^{5}$ In 2012, small (between 5 and 99 employees) and micro (less than 5 employees) businesses made up $99.0 \%$ of the Canadian construction industry's workforce and accounted for $72.7 \%$ of the total share of nominal GDP in the Canadian construction industry (Leung et al. 2008).
} 


\subsection{Case-Study Analysis: Process-Oriented Changes in the Italian Firm}

First, the 'as-is' state of the design process has been defined through an in-depth document analysis: the firm's quality management system (QMS) in particular has been used as the primary data source. Secondly, the 'transition' state of the design process has been studied through observation, interviews, document analysis, and process mapping of a BIM pilot project implemented by the Italian firm. Lastly, the 'to-be' state of the design process has been envisioned through the review of the literature and international standards about BIM and digital design process. To conclude, the three states of the design process ('as-is', 'transition', and 'to-be') have been cross-compared to identify the differences between one another. This last step has led to identify the process-oriented changes, which the adoption of digital technologies brought on within the firm, as well as the ones that still need to be implemented in order to facilitate the achievement of the full benefits of digitalization.

\subsection{Case-Study Analysis: Organizational Changes in the Canadian Firm}

The 'as-is' state of the firm's organizational structure has been defined, as first step, through an in-depth document analysis: the firm's human resources (HR) database, which included all the supervisor-employee couples, has been used as the primary data source. Secondly, the 'transition' state of the organizational structure has been defined by distributing a questionnaire to employees, which asked them to identify the peers they referred to for advice and help about digital technologies and processes. The data gathered have been then analyzed by using social network analysis. Lastly, the 'to-be state' of the organizational structure has been envisioned through a literature review about the new business models enhancing digital knowledge management, as well through interviews with the firm's top management.

\section{Findings}

\subsection{Process-Oriented Changes}

Data collection and analysis through the case study of the Italian firm has led to identification of the process-oriented changes that the adoption of digital technologies brought on within the firm (see Table 1), as well as the ones still to be implemented in order to gain the full benefits of digitalization (see Table 2). Because of the multidimensional nature of the changes associated with digitalization, also some 
Table 1 Changes within the Italian firm brought on by digital technologies' adoption (Employer's information requirements; BIM execution plan)

\begin{tabular}{l|l|l}
\hline Process & Organization & Technology \\
\hline $\begin{array}{l}\text { Improved information } \\
\text { exchange between the } \\
\text { architecture (A) and } \\
\text { engineering (E) teams AND } \\
\text { between the A and } \\
\text { 'rendering' (R) teams }\end{array}$ & $\begin{array}{l}\text { Enlarged marketing and } \\
\text { business opportunities }\end{array}$ & $\begin{array}{l}\text { New hardware, software, and } \\
\text { tools implemented }\end{array}$ \\
\hline $\begin{array}{l}\text { Improved collaboration } \\
\text { between A and E teams }\end{array}$ & $\begin{array}{l}\text { New roles and } \\
\text { responsibilities }\end{array}$ & \\
\hline $\begin{array}{l}\text { Integrated decision-making } \\
\text { of the A and E teams }\end{array}$ & $\begin{array}{l}\text { BIM skills and capabilities } \\
\text { acquired by A and E teams }\end{array}$ & \\
\hline $\begin{array}{l}\text { Improved consistency of the } \\
\text { A and E deliverables }\end{array}$ & & \\
\hline $\begin{array}{l}\text { Reduced coordination effort } \\
\text { (file exchange) between the A } \\
\text { and R teams }\end{array}$ & & \\
\hline $\begin{array}{l}\text { Reduced file production by } \\
\text { the A and E teams }\end{array}$ & & \\
\hline
\end{tabular}

Table 2 Changes still to be implemented to gain the full benefits of digitalization

\begin{tabular}{l|l|l}
\hline Process & Organization & Technology \\
\hline $\begin{array}{l}\text { Preliminary agreement with } \\
\text { the client about BIM } \\
\text { requirements (EIR, BEP, } \\
\text { etc.) }\end{array}$ & $\begin{array}{l}\text { BIM skills and capabilities } \\
\text { acquired by all the BU } \\
\text { involved in projects }\end{array}$ & $\begin{array}{l}\text { Set-up of the BIM } \\
\text { environment and related } \\
\text { procedures (graphic standard, } \\
\text { BIM libraries, etc.) }\end{array}$ \\
\hline $\begin{array}{l}\text { Preliminary definition of } \\
\text { project parties' roles and } \\
\text { responsibilities }\end{array}$ & & \\
\hline $\begin{array}{l}\text { BIM use } \text { in all the phases of } \\
\text { the design process }\end{array}$ & & \\
\hline $\begin{array}{l}\text { BIM adoption by all the } \\
\text { business units (BU) involved } \\
\text { in a project }\end{array}$ & & \\
\hline $\begin{array}{l}\text { Preliminary evaluation of } \\
\text { project parties' BIM-skills } \\
\text { and competencies }\end{array}$ & & \\
\hline
\end{tabular}

organizational and technological changes have been identified. These findings have been categorized according to the three primary dimensions of digitalization as proposed by Poirier et al. (2015). According to her model, in fact, key components of digitalization fall into three categories: process, organization, and technology. 


\subsection{Organizational Changes}

Data collection and analysis through the case study of the Canadian firm has led to identification of the organizational changes that the adoption of digital technologies brought on within the firm, as well as the ones still to be implemented in order to facilitate the achievement of the full benefits of digitalization.

Specifically, data gathered through the questionnaire distributed to the firm's employees has led to identify a multidisciplinary network of professionals acknowledged by other peers as informal 'go-to' people for advice and help in digital technologies and processes. Although these employees were playing a significant role within the firm since they were helping other colleagues to get their work done, they were not formally acknowledged by the existing organizational structure ('asis' state). Therefore, besides the formal roles and responsibilities as defined by the existing organizational structure, informal roles and relationships for advice and help in digital technologies and processes were in place too. This was the 'transition' state of the firm's organizational structure.

Because of the productivity inefficiencies associated with this 'transition' state, an organizational reconfiguration has been proposed to the firm's top-management defining a 'to-be' state of the organizational structure. This 'to-be' state meant the formal acknowledgment of this informal network of 'go-to' people through the creation of a support group for digital technologies and processes at the firm-level. New roles, responsibilities, and relationships have been therefore defined.

\section{Discussion}

To interpret and describe the significance of our findings, we framed the results of our study according to two out of the three BIM capability stages proposed by Kassem and Succar (2017) because of the minor distribution rate of the collaboration and integration processes in comparison to the modeling ones.

\subsection{Collaboration}

The findings of this study show that there is a need to enhance collaboration between the owner/client and the project parties starting from the early stages of the design process. In line with this view, it emerged the need for the owner to be more involved and active in defining and sharing with the involved parties the project requirements since the early phases of the process. Additionally, relationships, roles, and responsibilities within and between firms must be clearly defined in order to facilitate the set-up of a work environment that is conducive to digital innovation and that aim to enhance a dynamic network of teams. 


\subsection{Integration}

Furthermore, there is a need to facilitate and strengthen integration between project participants in order to improve information exchange and performance simulation according to different parameters, like embodied energy, and so on.

Additionally, the preliminary assessment of the digital skills and capabilities of project participants is also a significant topic, which came out from the findings of this study, and that is recommended in order to avoid time and cost overruns. Lastly, it also emerged the need to define standards and procedures to be shared internally, that means within firms, and externally, alias across the supply chain.

\section{Final Considerations and Future Directions}

The digitalization of the AEC industry is rapidly increasing and shows potential to improve industry productivity and competitiveness, as well as process efficiency and products' quality. Researchers and practitioners are already devoting significant efforts to promote the adoption of digital technologies. However, a larger and three-fold focus (technology, process, and organization) is necessary to enable the achievement of the full benefits of digitalization. Interactions and effects of digital transformation on processes and organizational models used by most projects and firms need to be explored. This creates a demand for looking at new forms of process and organization, and the impact of these on the architecture of work, as well as the socio-technological context required for facilitating these changes.

To investigate this point, this research used a mixed-method case-study approach, which included an extended case-study analysis of two different A/E firms: one in Italy and one in Canada. Specifically, the case study of the Italian firm has meant understanding in practice the process-oriented changes and the new forms of process associated with digitalization. The case study of the Canadian firm has been rather analyzed to identify how the adoption of digital technologies affects the existing organizational setting and how this one can be reconfigured to facilitate the achievement of the full benefits of digitalization.

Regarding the process-oriented changes and the new forms of process, the results indicate that there is a need for implementing collaborative and integrated processes within and between architectural and engineering firms, in addition to the modeling ones associated with the adoption of digital technologies. On the other side, data collection and analysis about the organizational changes and the new forms of organization reveal that more dynamic and networked organizational models should be implemented in order to facilitate digital knowledge creation, diffusion, and utilization within firms and between firms.

Regarding the future directions of this research topic, both researchers and practitioners involved in the digital transformation of the AEC industry can keep to make 
use of analysis methods for change management and get a valid support from a set of applied investigations and research activities, such as:

- Collection and analysis of benchmarking data through the analysis of additional case studies;

- Interpretation of changes associated with the adoption of digital technologies by deepening investigations on industry best practices;

- Analysis and comparison of strategies for digital transformation in relation to different markets and diverse contexts (cultural, legal, etc.).

\section{References}

\section{Articles}

Barbosa F, Woetzel J, Mischke J, Ribeirinho MJ, Sridhar M, Parsons M, Bertram N, Brown S (2017) Reinventing construction: a route to higher productivity. McKinsey \& Company

Burawoy M (1998) The extended case method. Sociol Theory 16(1):4-33

Chinowsky P, Diekmann J, Galotti V (2008) Social network model of construction. J Constr Eng Manag 134(10):804-812

Chinowsky P, Taylor J (2012) Networks in engineering: an emerging approach to project organization studies. Eng Project Organ J 2(1-2):15-26

Eisenhardt K (1989) Building theories from case study research. Acad Manag Rev 14(4):532-550

Gerbert P, Castagnino S, Rothballer C, Renz A, Filitz R (2016) Digital in engineering and construction. The transformative power of building information modelling. The Boston consulting group, pp 2-18

Industry Canada (2014) Establishments: construction (NAICS 23), Canadian Industry Statistics. Available at: http://www.ic.gc.ca/app/scr/sbms/sbb/cis/gdp.html?code=11-91andlang=eng (Accessed 19 March 2014)

Kassem M, Succar B (2017) Macro BIM adoption: comparative market analysis. Autom Constr 81:286-299

Leung D, Césaire M, Yaz T (2008) Productivity in Canada: does firm size matter?. Bank of Canada review, pp 5-14

Picon A (2016) From authorship to ownership. Archit Des 86(5):36-41

Poirier E, Staub-French S, Forgues D (2015) Embedded contexts of innovation. Constr Innov 15(1):42-65

Remes J, Mischke J, Krishnan M (2018) Solving the productivity puzzle: the role of demand and the promise of digitization. Int Product Monit 35:28

Zheng X, Le Y, Chan APC, Hu Y, Li Y (2016) Review of the application of social network analysis (SNA) in construction project management research. Int J Proj Manag 34(7):1214-1225

\section{Websites}

http://bimtopics.civil.ubc.ca/ http://www.ebc-construction.eu 
https://www.ic.gc.ca/

http://www.ebc-construction.eu/

Open Access This chapter is licensed under the terms of the Creative Commons Attribution 4.0 International License (http://creativecommons.org/licenses/by/4.0/), which permits use, sharing, adaptation, distribution and reproduction in any medium or format, as long as you give appropriate credit to the original author(s) and the source, provide a link to the Creative Commons license and indicate if changes were made.

The images or other third party material in this chapter are included in the chapter's Creative Commons license, unless indicated otherwise in a credit line to the material. If material is not included in the chapter's Creative Commons license and your intended use is not permitted by statutory regulation or exceeds the permitted use, you will need to obtain permission directly from the copyright holder.

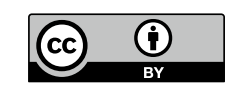

